\title{
Surface Chemistry Elucidation on Effect of Fruit Garbage Effective Microorganisms Product in Enhancing Fresh and Hardened Properties of Concrete
}

\author{
Mahmud Abba Tahir ${ }^{1}$ Muhammad Nura Isa ${ }^{2}$ Haruna Adamu ${ }^{3,4^{*}}$ Muhammad Magaji Garba ${ }^{5}$ \\ 1.Department of Building, Federal Polytechnic Bauchi \\ 2.Department of Building, Abubakar Tafawa Balewa University Bauchi \\ 3.Department of Environmental Management Technology, Abubakar Tafawa Balewa University Bauchi \\ 4.Department of Chemistry, Abubakar Tafawa Balewa University Bauchi \\ 5.Department of Building, Ahmadu Bello University, Zaria
}

\begin{abstract}
This study assessed and elucidated the influence of fruit garbage effective microorganisms' liquid product in improving the strength and other properties of concrete in terms of surface chemistry when added to concrete as partial replacement of mixing water. One control specimen was made along with four different mixes of 3, 5, 10 and $15 \%$ of the locally made liquid bio-product as replacement of the required mixing water during the concrete production. The experiments conducted on both control and liquid bio-product blended concretes were Proctor penetration test for setting time, workability and slump test for compressive strength. The results of the tests indicated that the locally made effective microorganisms' liquid product exerted retarding effect on the setting time of the blended concretes, as well as enhanced their workability. The result further indicated that, amongst all the locally made liquid bio-product blended concretes, the concrete specimen with $3 \%$ content possessed the highest compressive strength of $29.8 \mathrm{~N} / \mathrm{mm}^{2}$ and $35.5 \mathrm{~N} / \mathrm{mm}^{2}$ at 28 and 56 curing days, respectively. All these enhanced concrete properties were influenced by changing the surface hydration behaviour of cement in the concrete mixture, which varied widely upon addition of liquid bio-product at different percentage contents. Therefore, the addition of effective microorganisms' liquid product in the concrete mixture showed promising performance and thus, can be used as a low-cost and environmentally friendly admixture in the design of concrete.
\end{abstract}

Keywords: Effective Microorganisms, concrete, Compressive strength, workability, setting time

DOI: $10.7176 / \mathrm{CER} / 11-6-04$

Publication date:July $31^{\text {st }} 2019$

\section{Introduction}

For many years, concrete is doubtless the most widely used construction material due to its attractive strength characteristics (Mehta \& Monteiro, 2005). Despite its popularity in civil and construction engineering works, account by its impressive strength characteristics, concrete still has some properties that are not optimal for some applications. For example, when concrete is good enough to be used at normal construction environment, its performance becomes deteriorated when used in relatively adverse environments (Venkovic et al., 2014). Such apart, the most commonly problems faced in the used of concrete are setting time, workability, earlier and later strengths of concrete. Concrete-technology research has provided that the development of modern highperformance concrete with outstanding mechanical properties relies on an increased packing density of hydration products attainable by reducing the water-to-cement ratio (w/c) (Ulm et al., 2007). However, decreasing the water-to-cement ratio of a concrete mix is always accompanied with a drawback of loss of workability, which generally compensated by the addition of chemical admixtures. Chemical admixtures are introduced to improve some properties of concrete such as strength, workability, setting time and so on, but are expensive and not environmentally-friendly. As such, chemical admixtures can cause pollution or hazards to the environment. Accordingly, architects, builders and structural engineers must make critical decisions regarding the design of concrete mixtures that take environmental impacts into consideration by developing more environmentally sustainable concrete structures. Because concrete is also a contributor to climate change, changing the way we make concrete will go a long way in helping us maintain both a healthier natural environment and a robust built environment. Therefore, it is important to develop green concrete, which defined as a concrete that uses waste material as at least one of its components, or its production process does not lead to environmental destruction. In the recent time, the resort to low-cost admixture based on effective microorganisms (EM) was found to be effective in improving the compressive strength, workability of fresh concrete. Effective microorganisms' liquid product for concrete production is now being produced locally and used in the construction industry to promote environmental sustainability.

Fermentation is the main concept in the production of effective microorganisms' product. Nowadays, restaurants, vegetable markets, fruit markets and food processing industries produce decomposable waste such as 
fruits, vegetables and its peels, etc. in huge quantities. Management of these organic wastes is currently a major issue all over the world, as their generation is associated with a huge environmental impact (waste dumps, pollution, etc.). Hence, the decomposable waste thrown into the environment can be used to produce value added bio-product, which in turn reduces environmental pollution problem such as production of greenhouse gases by taking-off the decomposable garbage from the environment. Thus, these waste resources can be used to develop sustainable construction materials, for instance, effective microorganisms' product can be used as admixture, where it can replace chemical admixture. Effective microorganisms' product is one such value-added product that can also be produced by fermentation of fruit garbage wastes. Effective microorganisms consist of mixed cultures of beneficial, naturally occurring micro-organisms such as photosynthetic bacteria yeasts, and actinomycetes (Javaid, 2010). Condor et al. (2007) described these microorganisms as photosynthetic bacteria (phototrophic bacteria), which are independent self-supporting microorganisms. The beneficial bacteria are largely comprised of lactic acid bacteria that produce lactic acid from sugars, which increasing the decomposition of organic matter and ferment these materials more rapidly (Condor et al., 2007). In addition, the mixture of effective microorganisms' product contains yeasts that promote active cell division, which augmenting proliferation of lactic acid bacteria that also burst the production of lactic acid in the mixture. The Effective microorganisms' product is in liquid form which has broad applications in agriculture, environmental pollution management, household usage, medicine healthcare, disaster treatment.

The use of effective microorganisms' product in cement-based material has now begun to receive attention though still at slow rate. The use of effective microorganisms' liquid product as admixture in concrete has been slowed down by a lack of understanding of the mechanism involved in the reaction between cement and effective microorganisms' liquid product and thus, a well explanation on reaction mechanism is still lacking in the literature. Therefore, there is a need to explain the surface chemistry behind the influence of effective microorganisms' liquid product in improving fresh and hardened properties of concrete due to chemical interaction between the applied liquid bio-product and internal microstructure of cement because of its inclusion in concrete formation.

\section{Materials and Methods \\ 2.1 Materials}

The materials used in the study include effective microorganisms' product, ordinary Portland cement (OPC), river sand and coarse aggregate. The OPC used was Ashaka brand conforming to BS EN 197-1(2000). River sand was obtained from local dealers and sieve analysis was undertaken using sieves conforming to BS 410-1 (2000). The fruits and vegetable wastes used were obtained from the major fruits and vegetable market in Bauchi town. The fruits and vegetables garbage used include mango, pineapple, orange, banana, water melon, green leaves, cucumber and cabbage. The choice of these fruits and vegetables garbage was based on their availability at the time of this research. Fig. 1 shows some of the fruit garbage used in the research and the effective microorganisms' product formed. The bio-product was produced in the laboratory through the natural process of fermentation of fruits and vegetables garbage. The initial bio-product was further activated using sugarcane molasses and its final $\mathrm{pH}$ value was 3.80 was recorded after 10 days of activation period.
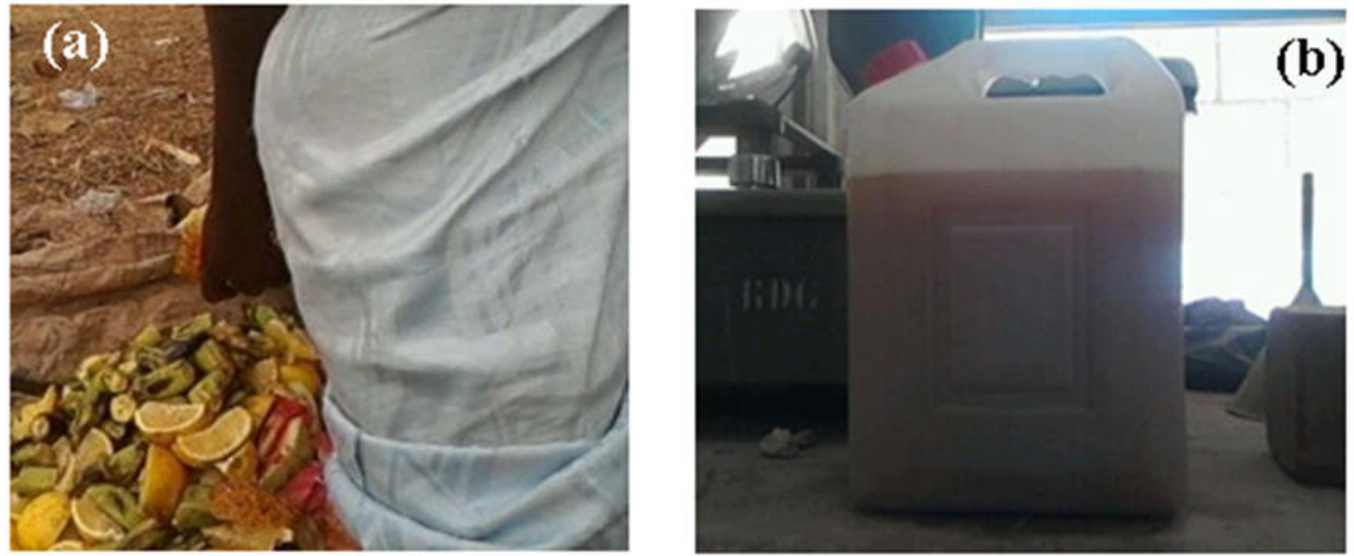

Figure 1. (a) Fruits wastes and (b) locally made effective microorganisms' liquid product

\subsection{Enumeration and identification of microorganisms}

The viable cell count of the sample was determined using spread plate method. The sample was agitated to mix thoroughly. $10 \mathrm{ml}$ was then pipette into equal $90 \mathrm{ml}$ of sterile normal saline to form a stock solution. Serial dilutions of the stock solution were carried out to obtain dilutes of $10^{-1}$ to $10^{-3}$. Then $0.1 \mathrm{ml}$ of $10^{-3}$ dilution in 
duplicate was aseptically transferred into sterile nutrient agar and potato dextrose agar plates, respectively. A sterile bent glass rod was used spread inocula on the surface of the culture media. The inoculated nutrient agar plates were incubated at $37^{\circ} \mathrm{C}$ for 24 hours while the potato dextrose agar plates were incubated at $25-27^{\circ} \mathrm{C}$ for 72 hours.

After the incubation period, the nutrient agar plates were observed for bacterial growth while the potato dextrose agar plates were observed for fungal colonies, the number of bacterial and fungal colonies were counted, and the results of the count was expressed as colony forming unit per milliliter ( $\mathrm{cfu} / \mathrm{ml})$.

\subsection{Mixture Proportions, Casting and Curing of specimens}

Two samples of concrete mixtures were designed and labeled "Sample SC" and "Sample SE". Sample SC was the control mixture and contained Portland cement (Ashaka cement), aggregate and water. Sample SE contained Portland cement, aggregate and water, in which 3, 5, 10 and 15\% of effective microorganisms' product were used in the concrete mix as partial replacement of total water content required in each of the concrete constructions, respectively. Generally, a single mix proportion was used in the design of the mix. The mix proportion adopted is in the ratio of 1:2:4. This proportion was adopted in order to have basis for comparison and to investigate the behaviour of each of the concrete constructed. Setting time tests was carried out to judge the effect of the effective microorganisms' product on both initial and final setting time of cement. The setting time was measured by performing the Proctor penetration test as described in the literature (Han \& Han, 2010). Workability measurement on fresh concrete was also carried out in accordance with specified fresh concrete standard, BS 1881: Part 102: 1983, Method for Determination of Slump. Sixty cubes of 100mm x 100mm x $100 \mathrm{~mm}$ cubes were produced for the compressive strength tests. Sample specimens for compression test were measured for density before crushing. The compressive strength test was carried out in accordance with BS EN 12390-7: 2009. Sample specimens were cured by immersion curing method and were tested at age of 7, 14, 28 and 56 days, respectively.

\section{Results and Discussions}

\subsection{Enumeration and identification of microorganisms}

The characteristics of the fruit garbage product solution obtained after 10 days of fermentation were analysed for microbial enumeration and identification and the results obtained is shown in Table 1. The bacterial and fungal counts was found to be $4.6 \times 10^{4}$ and $5.0 \times 10^{3}$, respectively and thus, bacteria colonies were the dominant microorganisms. From the analysis, various bacterial colonies were observed and later identified based on their colonial morphology, cell morphology, a group's reaction and reaction to some biochemical tests which includes catalase, coagulase and spore staining. The dominant bacteria population found was an accumulation of Lactobacillus specie and Bacillus subtilis. Lactobacillus specie is a lactic acid bacterium that produces lactic acid from sugars, which increasing the decomposition of organic matter during fermentation (Condor et al., 2007). It is therefore the lactic acid bacteria that was responsible for the final $\mathrm{pH}$ of 3.8 of the EM liquid product, which enhanced the breakdown of fruit garbage and fermented the garbage materials within 10 days more rapidly. On the functionality of Bacillus subtilis in the fermentation medium, it produces catalase that has been reported to exhibit a growth-promoting effect on lactobacilli (Hosoi et al., 2000). Bacillus subtilis is a growth-supporting microorganism, as it secretes large amounts of proteins into the growth medium (Yang et al., 2011). In the vein, fungal colonies were identified microscopically using lactophenol cotton blue after observing their colonial morphology. The fungal colonies comprised of Saccharomyces specie and Aspergillus Niger. Saccharomyces specie synthesises bio-active substances such as photo-hormones and enzymes that promote active cell division. Hence, these secretions provided useful substrates for the replication of lactic acid bacteria during the fermentation process of fruit garbage. However, the manifestation of Aspergillus Niger in the EM liquid product confirmed that the material used for the production of bio-liquid product was mainly fruits and vegetables waste, as this microorganism is a fruits and vegetables fungal spore (Schuster et al., 2002).

Table1. Results of Microbiological analysis

\begin{tabular}{ccccc}
\hline $\begin{array}{c}\text { Sample } \\
\text { code }\end{array}$ & $\begin{array}{c}\text { Bacterial Count } \\
\mathrm{cfu} / \mathrm{ml}\end{array}$ & $\begin{array}{c}\text { Fungal Count } \\
\mathrm{cfu} / \mathrm{ml}\end{array}$ & Bacteria Isolated & Isolated Fungi \\
\hline $\mathrm{S}_{1}$ & $4.6 \times 10^{4}$ & $5.0 \times 10^{3}$ & Bacillus subtilis & Aspergillus Niger \\
& & Lactobacillus specie & Saccharomyces specie \\
\hline
\end{tabular}

\subsection{Setting Time Tests}

Several procedures and assumptions are employed to established maturity to the estimation of the setting time (Jin et al., 2004; Pinto, 1999). The initial set to the final set difference is usually defined under the assumption that microstructure formation occurs to some extent due to hydration reaction within the cement atmosphere, which promptly begins even at the initial and final sets. The relationships between initial and final setting times 
of concrete for various contents of effective microorganisms' product is shown in Fig. 2. The initial setting time increased in the range between 110 and $225 \mathrm{~min}$, while the final setting increased from 218 to $443 \mathrm{~min}$. increasing the EM liquid product content led to considerable retardation of the initial and final sets. This may be attributed to the presence of molasses that was one contained in EM liquid product and was adsorbed onto surfaces of the hydrating cement particles and hydration product, resulted in a temporary coating film that perhaps responsible in lengthening the hydration process for a long period. Although the mechanism of this delay of cement hydration by sugary material in cementitious mixture has been partly understood (Juenger \& Jennings, 2002). However, this could be explained that the adsorbed molasses is conceivably flanked on hydrating cement particles, resulted in inhibition of the formation of calcium silicate hydrate (C-S-H) gel, which may be due to set-retarding effect exerted by molasses and limited cement to easily combine chemically with water molecules. The formation of flank on hydrating cement particles could be as a result of presence insoluble chemical complexes formed due to combination of sugar molecules and metals present in the cement, which coat the cement grain thereby hindered the chemical processes that harden the concrete. On the other hand, $\mathrm{H}$-bond network between molasses and water molecules is expected to be reduced in presence of metal salt, more so with $\mathrm{Ca}^{2+}$ in the cement and thus, accounts for the very low solubility of molasses in the cement/concrete mixture thereby flanked on hydrating cement particles and sluggish the chemical processes that harden the concrete.

The sluggishness of the chemical process that harden the formed concretes was clearly manifested when the percentage content of EM liquid product was increased from 3 to $10 \%$, thereby the difference in setting time of both initial and final was found to greater than that of conventional concrete. Conversely, replacement of water with $15 \%$ content of EM liquid product in the cement/ concrete mixture, it was found that both the initial and final setting time suddenly decreased, implying a lesser extent of disorganisation of H-bond network between molasses and water molecules in the mixture.

Although the $10 \%$ EM liquid product was found to be the optimal content that appropriately slow down the hydration process and elongated the setting time of the formed concrete, all the percentage replacement of locally made EM liquid product used also satisfied the BS12: 1991 standard that requires both the initial and final setting time of ordinary Portland cement should not be less than 45 minutes and not greater than 10 hours, respectively. Therefore, the EM liquid product can be used as hydration process retarding admixture.

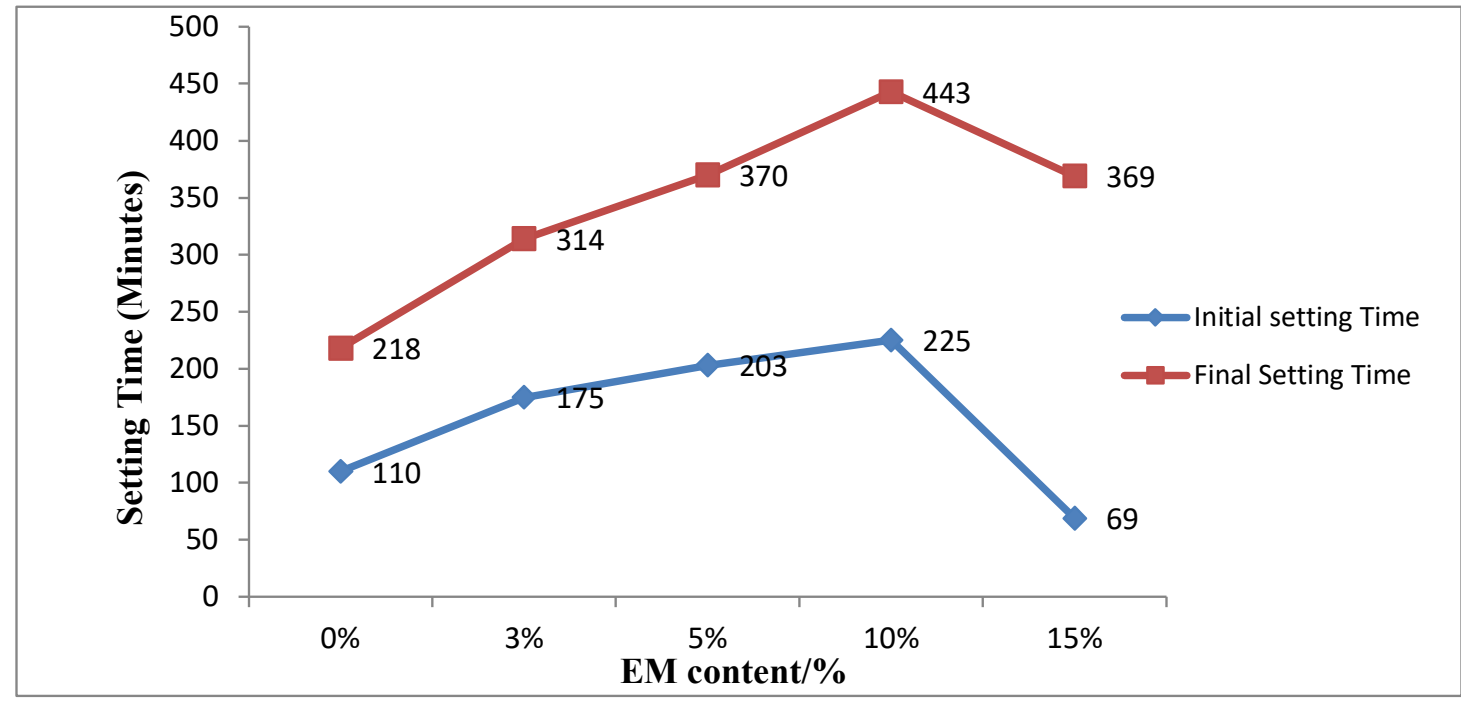

Figure 2. Setting time versus percentage contents of locally made EM liquid product

\subsection{Workability}

Fig. 3 shows the relationship between the average slump and type of mixes which were concrete mixture without EM liquid product labelled as control and concrete mixture blended with various percentage contents of EM liquid product. The slump height increased in the range between 76 and $145 \mathrm{~mm}$. The workability of the mixes was measured using slump test, which proved that the control mixture recorded low degree of workability, satisfied with low slump height. Meanwhile, the concrete mixture blended with various percentage contents of EM liquid product possessed higher workability than the control specimen. This indicates that EM liquid product was responsible in improving the workability of the moulded concretes. With the addition of 3,5 and $10 \%$ contents of EM liquid product in the concrete mixture, the workability of the mixes increased with slump height value of 76, 109 and $145 \mathrm{~mm}$, respectively. This indicates that as the workability of these mixes was higher than that of the control specimen, it implies unexpected increase in the water content of the EM liquid product 
blended concretes. One factor that is expected responsible for the improved workability of the EM blended concrete is deemed to be a chemical reaction that occurred between the alkaline cement pastes with the acidic EM liquid product, which produced water as one of the identified products of neutralisation reaction. The reaction was a stepwise that occurred via the hydration of calcium oxide in the cement that produced calcium hydroxide, which reacted with lactic acid present in the EM liquid product (see Eq. 1 and 2). Consequently, neutralisation reaction led to the increase in workability of the EM liquid product blended concretes due to autogenous increased water/cement ratio in the mixture and therefore, EM liquid product can be used as workability enhancing admixture.

$$
\begin{gathered}
\mathrm{CaO}+\mathrm{H}_{2} \mathrm{O} \rightarrow \mathrm{Ca}(\mathrm{OH})_{2} \\
\mathrm{Ca}(\mathrm{OH})_{2}+2 \mathrm{CH}_{3} \mathrm{CH}(\mathrm{OH}) \mathrm{CO}_{2} \mathrm{H} \rightarrow\left(\mathrm{C}_{3} \mathrm{H}_{5} \mathrm{O}_{2}\right)_{2} \mathrm{Ca}+2 \mathrm{H}_{2} \mathrm{O}
\end{gathered}
$$

Interestingly, no different effect was observed upon addition of $15 \%$ content of EM liquid product into the concrete, as its slump height recorded the same value of $145 \mathrm{~mm}$ as that of $10 \%$ EM liquid content. This may be connected to the characteristic interruption of hydration process due to presence of significant amount of lactic acid at saturated limit in the concrete that blocked the formation of water via neutralisation reaction. Thus, saturation limit at $15 \%$ may exist with no benefit to workability of the moulded concretes blended with EM liquid product, as the saturated amount of lactic acid in the concrete mixture blocked the hydration of $\mathrm{CaO}$ particles and thus, no further water was added to the water/cement ratio of the mixture. This means that the percentage content of EM liquid product should not exceed $10 \%$ required to be added into concrete mixture to achieve better workability. Consequently, it is important to determine the appropriate percentage content of EM liquid product needed to be added into concrete to achieve an improved workability economically, as adding a percentage content above an optimal limit appeared to be waste of admixture. A similar result was reported in the literature (Idris \& Yusof, 2018).

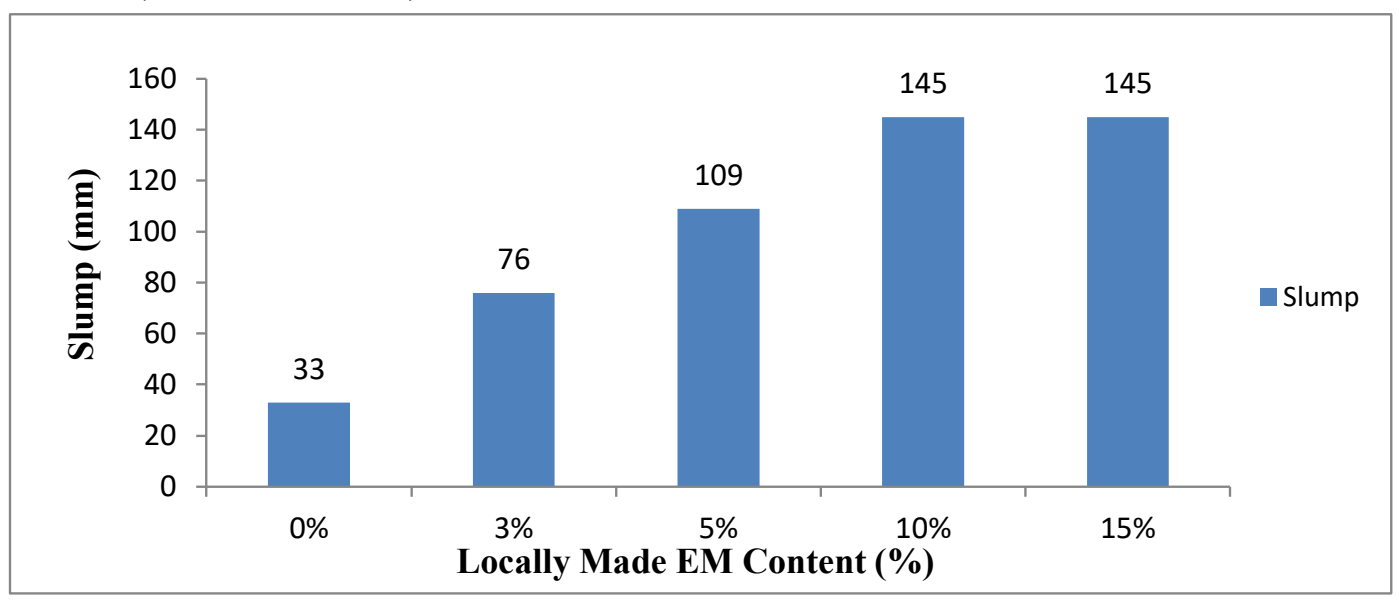

Figure 3. Slump heights versus locally made EM liquid product content

\subsection{Compressive strength}

The result of the compressive strength test is presented in Fig. 4. From the plot, it is obvious that one of the effects of EM liquid product on the performance of concrete is increasing the compressive strength of concrete. The autogenous increase in compressive strength of concrete happens in the presence of moisture or water, which occurs through hydration of un-hydrated cement particles followed by carbonation of dissolved calcium hydroxide (Samani \& Attard, 2014). It is therefore conceived that hydration of calcium oxide in the concrete mixture produced calcium hydroxide, which reacted with carbon dioxide that descended from the atmosphere unto the surface of concrete matrix and the reactions resulted in production of calcium carbonate (see Eq. 3 and 4). Because of compatibility with cementitious compositions, calcium carbonate deemed to be responsible in increasing compressive strength by padding the voids, porosities and cracks in concrete. Noticeably, it is important to assert that the much likely factors of the improvement of strength is expected to be a surface chemical reaction that occurs between the alkaline cement paste with the acidic EM liquid product that produce a new and identified substance of calcium carbonate. It is this new substance with property and behaviour similar to hardened igneous rocky materials, which subsequently strengthen the internal bonding in presence of water or moisture and finally the concrete becomes denser and then exhibits improved increase in compressive strength and resistance to the unfriendly conditions in the environment. Hence, the success of autogenous increase in compressive strength of concrete depends strongly on presence of water or moisture in the surrounding environment or concrete mixture and thus, the correlation between compressive strength and addition of water or moisture to moulded concrete is positive. 


$$
\begin{aligned}
& \mathrm{CaO}+\mathrm{H}_{2} \mathrm{O} \rightarrow \mathrm{Ca}(\mathrm{OH})_{2} \\
& \mathrm{CaO}+\mathrm{CO}_{2} \rightarrow \mathrm{CaCO}_{3}+\mathrm{H}_{2} \mathrm{O}
\end{aligned}
$$

The data illustrated in Fig. 4 shows that concrete blended with 3\% content was the only specimen with an improved increase in compressive strength compared to all other specimens including the control. At 28- and 56days maturity ages, the concrete with $3 \%$ EM product recorded a compressive strength of $29.8 \mathrm{~N} / \mathrm{mm}^{2}$ and $35.5 \mathrm{~N} / \mathrm{mm}^{2}$ respectively, which were higher than the corresponding values for control specimen. However, all other specimens showed decreased in compressive strength at all curing ages compared to the control specimen, which may be attributed to the interruption or seizure of the hydration process in the cast concretes caused by the saturated increase in the percentage content of EM liquid product. Meaningfully, 3\% content was the optimal amount above which a saturation limit of lactic acid in the concrete mixture was reached and that prevented the hydration of $\mathrm{CaO}$ particles and successive carbonation process to occur in the affected concretes. This perhaps was mainly the cause for the decrease in compressive strength of the affected concretes during the curing ages. This finding is consistent with the previous study which reported that increase in the percentage of EM affects the hydration process with attendant decrease in compressive strength (Andrew et al., 2012).

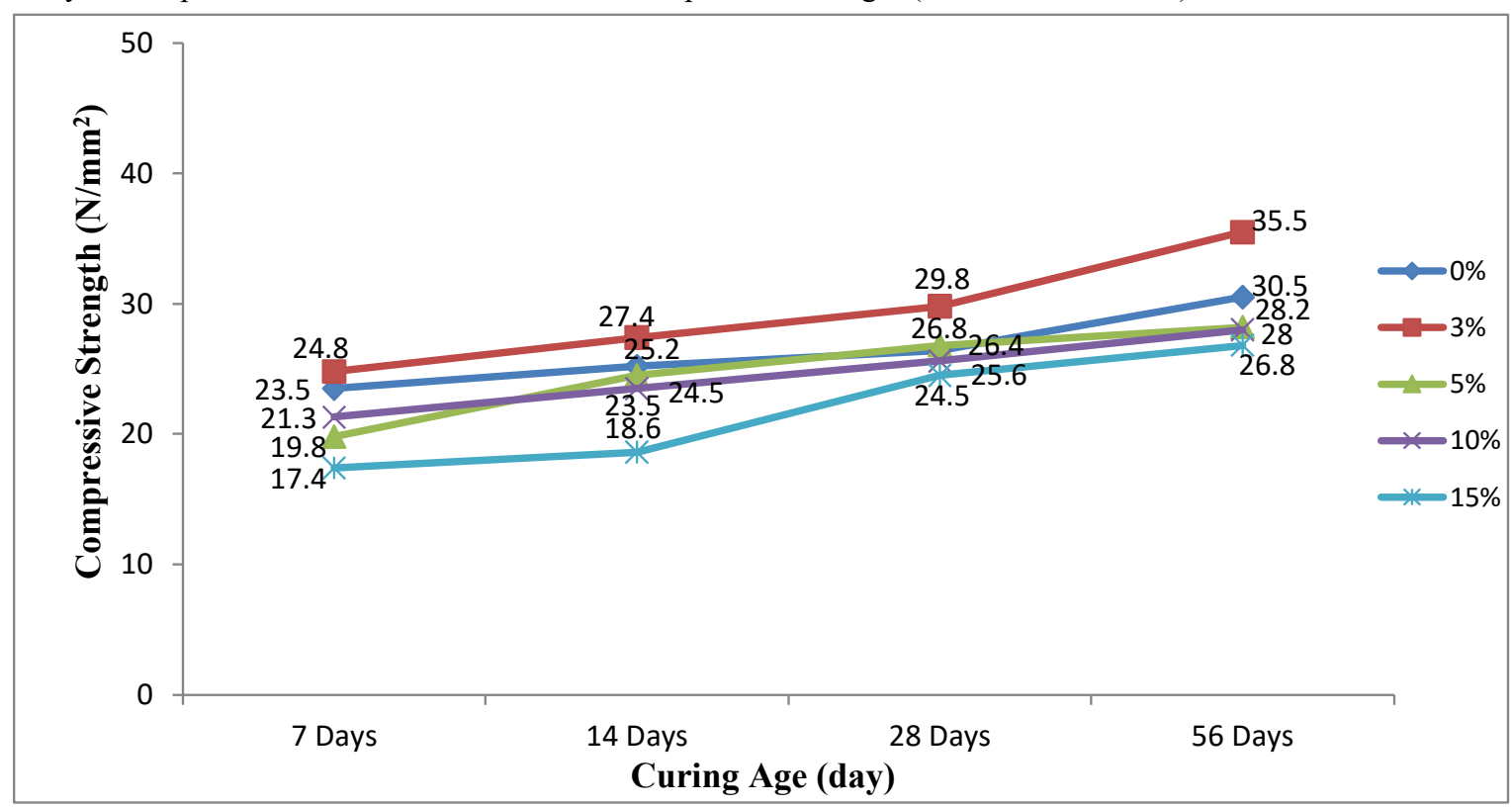

Figure 4. Compressive strength versus curing age

\section{Conclusion}

Application of fruit garbage effective microorganisms' liquid product as an admixture is quite promising approach in concrete technology compared to existing admixtures due to its compatibility with concrete compositions and sustainability. At optimal percentage content, it is capable of enhancing fresh and hardened properties of concrete. Moreover, the conversion of fruits and vegetables wastes to value added liquid admixture for concrete production could turn to be a way of exterminating or reducing emission of greenhouse gases like methane and nitrous oxides caused by indiscriminate throw of fruits and vegetables garbage into the environment. With the use of optimal percentage content of effective microorganisms' liquid product, a retarding effect on setting time as well as an autogenous increase in workability and compressive strength of concrete was observed compared to control specimen. These enhanced properties were driven by surface chemical reaction between the acidic composition of the effective microorganisms' liquid product and hydrating particles of cement. Therefore, the use of this liquid bio-product exposes way of making an environmentally friendly, sustainable and cost-effective admixture for enhancing fresh and hardened properties of concrete.

\section{Acknowledgement}

We are sincerely grateful to Tertiary Education Trust Fund, Nigeria (TETFUND) for the financial provision made available for this research work under the auspices of Institutional-Based Research Grant (processed number- FPTB/RDU/TETFUND/RP/2016/0033). The authors also thank the technicians for all the laudable experimentations and testing carried out in their laboratories. 


\section{References}

Andrew, T. C. S., Syahrizal, I. I., \& Jamaluddin, M. Y. (2012), "Effective microorganisms for concrete (EMC) and its effects on the mechanical properties of concrete", Awam International Conference on Civil Engineering, Penang.

BS Standard BS EN 197-1. (2000), “Cement: Composition, specifications and conformity criteria for common cements", BSI, Linford wood, Milton Keynes MK14 6LE, U.K.

BS Standard BS 410-1. (2000), “Test sieves: Technical requirements and testing. Test sieves of metal wire cloth', BSI, Linford wood, Milton Keynes MK14 6LE, U.K.

British Standard Institution. (1983), “Method for Determination of Slump”, BS 1881, Part 102, London, British Standard Institution, BSI.

BS Standard EN 12390-7. (2009), “Testing hardened concrete. Density of hardened concrete’, BSI, Linford wood, Milton Keynes MK14 6LE, U.K.

BS 12:1991. (1991), “Specification for Portland cement. British Standards Institution', BSI, London.

Condor, A. F., Gonzalez, P., \& Lakre, C. (2007), 'Effective microorganisms: Myth or reality?' The Peruvian Journal of Biology, 14, 315-319.

Han, M-C., \& Han, C-G. (2010), "Use of maturity methods to estimate the setting time of concrete containing super retarding agents", Cement and Concrete Composites 32, 164-172. https://doi.org/10.1016/j.cemconcomp.2009.11.008

Hosoi, T., Ametani, A., Kiuchi, K., Kaminogawa, S. (2000), "Improved growth and viability of lactobacilli in the presence of Bacillus subtilis (natto), catalase, or subtilisin', Canadian Journal of Microbiology 46, 892-897. https://doi.org/10.1139/w00-070

Idris, I. H. M., \& Yusof, N. Z. (2018), “'Development of low thermal mass cement-sand block utilizing peat soil and effective microorganism', Case Studies in Construction Materials 8, 8-15. https://doi.org/10.1016/j.cscm.2017.11.004

Javaid, A. (2010), “Beneficial microorganisms for sustainable agriculture”' Sustainable Agriculture Reviews 4, 347-369.

Jin, H. L., Kim, K. M., Woo, J. W., Han, M. C., \& Han, C. G. (2004), “Quality of concrete using recycling water with the kinds and contents of saccharic based stabilizing agent', Proceeding of Ann Meeting Korean Concrete Institute 16(1), 660-663.

Juenger, M. G., \& Jennings, H. M. (2002), "New insights into the effects of sugar on the hydration and microstructure of cement pastes", Cement Concrete Research 32(4), 393-399. https://doi.org/10.1016/S0008-8846(01)00689-5

Mehta, P. K., \& Monteiro, P. J. M. (2005), “Concrete microstructure, properties and material”, Tata McGrawHill Publishing Company Ltd., Delhi, 2005,121-198.

Pinto, R. C. A., \& Hover K. C. (1999), “Application of maturity approach to setting times", ACI Material Journal 96(6), 686-691.

Samani, A. K., \& Attard, M. M. (2014), “Lateral strain model for concrete under compression”, ACI Structural Journal 111(2), 441-451.

Schuster, E., Dunn-Coleman, N., Frisvad, J. C., \& Van Dijck, P. W. (2002), “On the safety of Aspergillus nigera review", Applied Microbiology and Biotechnology 59(4-5), 426-435. https://doi.org/10.1007/s00253002-1032-6

Ulm, F-J., Vandamme, M., Bobko, C., Alberto, O. J., Tai K., \& Ortiz, C. (2007). "'Statistical indentation techniques for hydrated nanocomposites: concrete, bone, and shale', Journal of American Ceramic Society 90(9), 2677-2692. https://doi.org /10.1111/j.1551-2916.2007.02012.x

Venkovic, N., Sorelli, L., \& Martirena, F. (2013), "Nanoindentation study of calcium silicate hydrates in concrete produced with effective microorganisms-based bio-plasticizer', Cement Concrete Composites 49, 127-139. https://doi.org/10.1016/j.cemconcomp.2013.12.003

Yang, C-K., Ewis, H. E., Zhang, X., Lu, C-D., Hu, H-J., Pan Y., Abdelal, A. T., \& Tai, P. C. (2011), Nonclassical protein secretion by bacillus subtilis in the stationary phase is not due to cell lysis", Journal of Bacteriology 193(20), 5607-5615. https://doi.org /10.1128/JB.05897-11 